\title{
EDITORIAL
}

\section{Management of tuberculosis in HIV infection: where T-cells matter}

\author{
M. Sester*, C. GiehI ${ }^{\#}$, U. Sester ${ }^{\Uparrow}$ and A. Meyerhans ${ }^{+}$
}

드 ven 127 years after Robert Koch's identification of Mycobacterium tuberculosis as the causative agent of tuberculosis (TB), the diagnosis of active disease still depends in many parts of the world on the same tools that Koch has used: specifically staining of the bacilli and visual observation by microscopy [1]. Thirty years later, von Pirquet developed the tuberculin skin-test (TST), which, instead of observing the pathogenic microbe itself, measures the immunological response to it [2]. We now know that the specific induration in the skin-test is mediated by specifically activated T-lymphocytes that elicit a delayed-type hypersensitivity (DTH) response via production of a variety of inflammatory cytokines. While both test systems are still widely used, their sensitivity is highly variable and ranges from 20 to $60 \%$ for microscopy $[3,4]$, and 67 to $80 \%$ for skin-testing [5,6]. In patients with HIV infection and other forms of immunosuppression, the sensitivity is even worse and far beyond being adequate for a modern diagnostic test $[7,8]$.

In their recent manuscript, LEIDL et al. [9] now compare the performance accuracy of the skin-test for diagnosing latent $M$. tuberculosis infection with two commercially available in vitro assays that measure interferon (IFN)- $\gamma$ production of T-cells after stimulation with $M$. tuberculosis-specific antigens. Their patient cohort comprised $128 \mathrm{HIV}$-infected individuals, of which 19 presented with active TB. The patients showed a varying degree of immunosuppression as evidenced by their absolute number of cluster of differentiation (CD)4-positive helper T-cells. Although all three assays rely on cytokine production predominantly from CD4 T-cells [10], the skin-test, the ELISA-based QuantiFERON TB gold in-tube assay (QFT-GIT), and the ELISPOT-based T.SPOT.TB assay showed variable performance that mainly depended on the CD4 T-cell counts. With T-cells over 250 per $\mu \mathrm{L}$ and in healthy controls, the QFT-G-IT and the TST were superior, although they exhibited decreasing performance upon increasing immunodeficiency. In contrast, the results of the ELISPOT-based T.SPOT.TB assay were independent of CD4 T-cell counts and performed markedly better in HIV patients with $<100$ CD4 T-cells per $\mu \mathrm{L}$. Based on previous publications [11-14] and the principles

\footnotetext{
*Dept of Transplant and Infection Immunology, Institute of Virology, and "Dept of Internal Medicine IV, University of the Saarland, Homburg, ${ }^{*}$ European Research and Project Office GmbH - Eurice, Saarbrücken, Germany. ${ }^{+}$ICREA and University Pompeu Fabra, Infection Biology Group, Dept of Experimental and Health Sciences, Barcelona, Spain.
}

CORRESPONDENCE: M. Sester, Dept of Transplant and Infection Immunology, Institute of Virology, University of the Saarland, Homburg, Germany. E-mail: martina.sester@uks.eu of the two in vitro assays [10, 15], this result is not entirely unexpected. In the QFT-G-IT assay, IFN- $\gamma$ is secreted into the supernatant, and the amount of cytokines is a rough correlate of the number of T-cells that were specifically activated by the $M$. tuberculosis antigen. In contrast, in the ELISPOT assay, a defined number of isolated peripheral blood mononuclear cells (PBMC) is used and the percentage of reactive cells is expressed as spotforming cells per 250,000 PBMC. Thus, by this normalisation to a defined number of PBMC, the cell loss due to progressive disease is at least partially compensated for. However, this clearly has a limit when the amount of M. tuberculosis-specific CD4 T-cells comes near to the detection limit of the ELISPOT assay. According to KARAM et al. [14], this seems to be the case below approximately $50 \mathrm{CD} 4 \mathrm{~T}$-cells per $\mu \mathrm{L}$ blood.

Other studies have already assessed the sensitivity of both in vitro $M$. tuberculosis tests with the skin-test in a head-to-head manner in HIV-infected individuals [11-13]. However, those studies were mainly restricted to patients with moderately advanced HIV infection, that had relatively little impact on test sensitivity [11], were performed in a low prevalence country [12], or compared test sensitivities between children and adults [13]. The strength of the present study by LEIDL et al. [9] is that it was performed in a high-prevalence country and it includes statistically robust data on HIV-infected patients with low CD4 T-cell counts. It is exactly these places, in which highly sensitive tests are needed most. The high prevalence of both microbes accounts for large numbers of co-infected individuals, in which the progressive immune dysfunction caused by HIV not only affects reliability of immune-based testing but also increases susceptibility to $M$. tuberculosis infection and progression from latent to active TB $[16,17]$.

What is the actual advantage of an increased sensitivity to detect an M. tuberculosis infection in HIV-positive patients? Clearly, patients profit from an earlier diagnosis of a latent infection as they can be provided with a preventive TB therapy before they might develop active disease and further spread the infection. In addition, the morbidity in this vulnerable population is reduced, especially in the absence of antiretroviral therapy. This is particularly important in countries with a high TB burden, as numerically more patients will be diagnosed and subsequently could benefit. However, as of now, those assays are not yet widely available and respective diagnosis frequently does not translate into the appropriate therapy. To improve this, there is an urgent need for a timely implementation of scientific achievements into clinical practice. This, however, can only be realised with respective political 
commitment and support. In this context, international networks such as the World Health Organization (WHO)- United Nations Programme on HIV / AIDS (UNAIDS) $[18,19]$, the WHO Stop-TB partnership [20], TB-NET [21], and EUCO-Net [22] are not only emphasising the need for a clear political backing but also advocating the importance of integrative approaches, bringing together a variety of disciplines and countries in order to allow for mutual feedback between basic scientists, clinicians, affected communities, and policy makers. This may then not only lead to an improved management of individual patients but ultimately also to a better global control of the M. tuberculosis burden.

\section{STATEMENT OF INTEREST}

None declared.

\section{REFERENCES}

1 Murray JF. Mycobacterium tuberculosis and the cause of consumption: from discovery to fact. Am J Respir Crit Care Med 2004; 169: 1086-1088.

2 von Pirquet C. Die Allergieprobe zur Diagnose der Tuberkulose im Kindesalter. Wien Med Wochenschr 1907; 57: 1370-1374.

3 Urbanczik R. Present position of microscopy and of culture in diagnostic mycobacteriology. Zentralbl Bakteriol Mikrobiol Hyg A 1985; 260: 81-87.

4 Steingart KR, $\mathrm{Ng} \mathrm{V}$, Henry M, et al. Sputum processing methods to improve the sensitivity of smear microscopy for tuberculosis: a systematic review. Lancet Infect Dis 2006; 6: 664-674.

5 Berkel GM, Cobelens FG, de Vries G, et al. Tuberculin skin test: estimation of positive and negative predictive values from routine data. Int J Tuberc Lung Dis 2005; 9: 310-316.

6 Edwards LB, Acquaviva FA, Livesay VT, et al. An atlas of sensitivity to tuberculin, PPD-B, and histoplasmin in the United States. Am Rev Respir Dis 1969; 99: Suppl., 1-132.

7 Johnson MP, Coberly JS, Clermont HC, et al. Tuberculin skin test reactivity among adults infected with human immunodeficiency virus. J Infect Dis 1992; 166: 194-198.

8 Pai M, O'Brien R. New diagnostics for latent and active tuberculosis: state of the art and future prospects. Semin Respir Crit Care Med 2008; 29: 560-568.

9 Leidl L, Mayanja-Kizza H, Sotgiu G, et al. Relationship of immunodiagnostic assays for tuberculosis and numbers of circulating CD4+ T-cells in HIV-infection. Eur Respir J 2010; 35: 619-626.

10 Mack U, Migliori GB, Sester M, et al. LTBI: latent tuberculosis infection or lasting immune responses to M. tuberculosis? A TBNET consensus statement. Eur Respir J 2009; 33: 956-973.

11 Rangaka MX, Wilkinson KA, Seldon R, et al. Effect of HIV-1 infection on T-cell-based and skin test detection of tuberculosis infection. Am J Respir Crit Care Med 2007; 175: 514-520.

12 Stephan C, Wolf T, Goetsch U, et al. Comparing QuantiFERONtuberculosis gold, T-SPOT tuberculosis and tuberculin skin test in HIV-infected individuals from a low prevalence tuberculosis country. AIDS 2008; 22: 2471-2479.

13 Mandalakas AM, Hesseling AC, Chegou NN, et al. High level of discordant IGRA results in HIV-infected adults and children. Int $J$ Tuberc Lung Dis 2008; 12: 417-423.

14 Karam F, Mbow F, Fletcher $\mathrm{H}$, et al. Sensitivity of IFN- $\gamma$ release assay to detect latent tuberculosis infection is retained in HIVinfected patients but dependent on HIV/AIDS progression. PloS One 2008; 3: e1441.

15 Andersen P, Munk ME, Pollock JM, et al. Specific immune-based diagnosis of tuberculosis. Lancet 2000; 356: 1099-1104.

16 Smieja MJ, Marchetti CA, Cook DJ, et al. Isoniazid for preventing tuberculosis in non-HIV infected persons. Cochrane Database Syst Rev 2000; 2: CD001363.

17 Guwatudde D, Nakakeeto M, Jones-Lopez EC, et al. Tuberculosis in household contacts of infectious cases in Kampala, Uganda. Am J Epidemiol 2003; 158: 887-898.

18 UN-AIDS. 2008 report on the global AIDS epidemic UNAIDS, July 2008. www.unaids.org/en/KnowledgeCentre/HIVData/ GlobalReport/2008/ Date last accessed: January 12, 2010; Date last updated: July 2008.

19 WHO, UNAIDS, PEPFAR. A guide to monitoring and evaluation for collaborative TB/HIV activities - 2009 revision. (WHO, UNAIDS, PEPFAR) 2009.

20 The global plan to stop TB 2006-2015. www.stoptb.org/globalplan Date last accessed: January 12, 2010; Date last updated: January 12, 2010.

21 Tuberculosis Network European Trialsgroup TB-NET. www.tbnet.org Date last accessed: January 12, 2010; Date last updated: January 12, 2010.

22 EUCO-Net. European Network for global cooperation in the field of HIV \& TB. www.euco-net.eu Date last accessed: January 12, 2010; Date last updated: January 12, 2010. 